IRA-International Journal of Education \& Multidisciplinary Studies

ISSN 2455-2526; Vol.07, Issue 01 (2017)

Pg. no. 46-52

Institute of Research Advances

http://research-advances.org/index.php/IJEMS

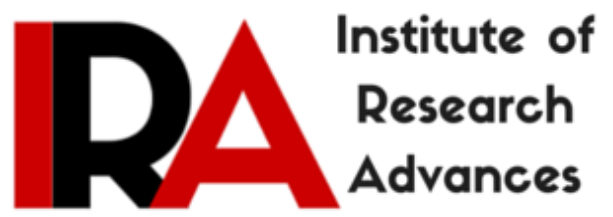

\title{
Economic Crisis and Poverty Induced Deviance on Female Teachers in Zimbabwe
}

\author{
Plaxcedes Chikunda ${ }^{1}$ Cynthia Dzimiri $^{2}$ Viola Ingwani ${ }^{3}$ \\ ${ }^{1,2}$ Lecturer, Sociology of Education, Great Zimbabwe University, Zimbabwe. \\ ${ }^{3}$ Lecturer, Educational Psychology, Great Zimbabwe University, Zimbabwe.
}

Type of Review: Peer Reviewed.

DOI: http://dx.doi.org/10.21013/jems.v7.n1.p5

\section{How to cite this paper:}

Chikunda, P., Dzimiri, C., \& Ingwani, V. (2017). Economic Crisis and Poverty Induced Deviance on Female Teachers in Zimbabwe. IRA International Journal of Education and Multidisciplinary Studies (ISSN 2455-2526), 7(1), 46-52. doi:http://dx.doi.org/10.21013/jems.v7.n1.p5

(C) Author.

\section{(cc) EY-NC}

This work is licensed under a Creative Commons Attribution-Non Commercial 4.0 International License subject to proper citation to the publication source of the work.

Disclaimer: The scholarly papers as reviewed and published by the Institute of Research Advances (IRA) are the views and opinions of their respective authors and are not the views or opinions of the IRA. The IRA disclaims of any harm or loss caused due to the published content to any party. 


\begin{abstract}
The study explores deviant activities that female teachers engage into due to the poverty induced by the economic crisis prevailing in Zimbabwe. The research was designed and conducted within the qualitative paradigm. The design adopted by the study was the survey. The methodology involved informal conversational interviews and focus group discussions. The study was conducted with a group of thirty female teachers who were also perusing their masters studies. The study established that female teachers engage in various deviant as teachers and as students due to the economic hardships that they find themselves in. Deviant acts as teachers include failure to attend to their classes, getting involved into peddling activities instead to augment the meagre income from government. Retailing of goods to pupils, giving less work to their pupils to reduce work load and many more. As students they are forced to engage in acts of plagiarism as well as missing lessons to attend to whatever business that can bring the much needed extra income.
\end{abstract}

\title{
Introduction and Background
}

The economic meltdown in Zimbabwe started in the early 2000s. This has raised levels of poverty for both women and men. However, according to Haralambos and Holborn (2000) the chances of being in poverty are not equally distributed. Some groups are much more prone to ending up in poverty than others, while the chances relating to particular groups change over time. As such, women who are left with fewer resources with which to manage the home and provide for the family are likely to feel the impact of poverty. In the case of Zimbabwe, poverty has been exacerbated by current economic trends, which have trapped many people especially professionals in a vicious cycle of low income. The middle class, in which teachers belonged to was eroded. Master of Education students, the bulk of whom are teachers are among those people caught up in vicious cycles of poverty. Due to their low incomes, the female students are increasingly depending on self-employment in the informal sector to augment their meagre salaries. It should be noted though that male students may have similar problems but the researchers' interest was on female students.

Poverty is likely to promote deviant behaviour among Master of Education students who have to cope with the heavy demands of university education, work as teachers and participate in the informal sector. The block release mode of entry is characterized by a packed school holiday program where students attend lectures at the university. It is also characterized by an open learning system where students do their assignments and prepare for semester examinations while at work. Thus, in an environment characterized by economic meltdown and poverty, the female student's study time is taken up by activities aimed at fighting poverty in the family. It was against this background that this study sought to examine poverty as a socio-economic factor that promotes deviance among Master of Education female students. The plight of teachers is brought to the limelight by Raymond Majongwe (People Magazine October, 31, 2008) when he says:

"in the 1980s a teacher could buy a house, in the 1990s a teacher could buy a car, but as things stand today, a teacher is so impoverished he cannot afford to buy even a pair of shoes."

The above statement serves to show how teachers have become relatively poor. As a result, female students are likely to experience social problems since they have to come to terms with their poverty and at the same time carry out their studies.

\section{Theoretical framework}

According to Haralambos and Holborn (2000), from a conflict perspective it is the failure of society to allocate resources and provide opportunities fairly that explains the problems of poverty. Poverty is not 
held to be the responsibility of those who suffer from it. Instead, such people are seen as victims. According to some conflict theorists, recent studies of poverty have found that those who rely upon state benefits for their income are among the largest groups of the poor (ibid). they further assert that if poverty is defined in relative terms, and the definition that is advanced means that benefit levels do not raise the recipient above the poverty line, then a great deal of poverty can simply be attributed to inadequate benefits. Mingione (1996), a conflict theorist argues that increases in poverty are linked to changes in the world economic system. Byrne (1999) agrees with Mingione that changes in the world economic systems have led to an increase in poverty. Haralambos and Holborn (2013), state that most conflict theorists move beyond explaining why particular individuals and groups are poor in an attempt to relate poverty to the organization of society as a whole. They claim that poverty is rooted in the very structure of society.

Deviance consists of those acts that depart from the norms and expectations of a given culture. To deviate means to drift away from a conventional trail. From a functionalist perspective deviance breaks social norms and values (Haralambos and Holborn, 2013). Merton (1957) argues that deviance results from the culture and structure itself. Beginning from the standard functionalist position of value consensus, he posits that all members of society share the same values. In all societies, there are institutionalized means of reaching culturally defined goals. For instance in Zimbabwe, as in most other countries, the most acceptable way of achieving success is through attaining educational qualifications. In his structural strain theory which is an extension of the functionalist perspective on deviance, Merton (1957) argues that the origins of deviance can be traced to the tensions that are caused by the gap between cultural goals and the means people have available to achieve those goals. According to the structural strain theory, societies are characterized by both culture and social structure. Culture establishes goals for people in society while social structure provides (or fails to provide) the means for people to achieve those goals (ibid). In a wellintegrated society, people use accepted and appropriate means to achieve the goals that society establishes. In this case, the goals and the means of the society are in balance. It is when the goals and means are not in balance with each other that deviance is likely to occur. This imbalance between cultural goals and structurally available means can actually lead an individual into deviant behavior.

Deviance consists of those acts that depart from the norms and expectations of a given culture. To deviate means to drift away from a conventional trail. From a functionalist perspective deviance breaks social norms and values (Haralambos and Holborn, 2013). Merton (1957) argues that deviance results from the culture and structure itself. Beginning from the standard functionalist position of value consensus, he posits that all members of society share the same values. In all societies, there are institutionalized means of reaching culturally defined goals. For instance in Zimbabwe, as in most other countries, the most acceptable way of achieving success is through attaining educational qualifications. In his structural strain theory which is an extension of the functionalist perspective on deviance, Merton (1957) argues that the origins of deviance can be traced to the tensions that are caused by the gap between cultural goals and the means people have available to achieve those goals. According to the structural strain theory, societies are characterized by both culture and social structure. Culture establishes goals for people in society while social structure provides (or fails to provide) the means for people to achieve those goals (ibid). In a wellintegrated society, people use accepted and appropriate means to achieve the goals that society establishes. In this case, the goals and the means of the society are in balance. It is when the goals and means are not in balance with each other that deviance is likely to occur. This imbalance between cultural goals and structurally available means can actually lead an individual into deviant behavior.

From the above discussion, it is clear that M Ed. female students, who are teachers who rely on a state salary, are among the poor especially at a time when Zimbabwe is experiencing economic hardships. The question then is how does poverty promote deviant activities? 


\section{The problem.}

Pursuing further studies, with a poor remuneration may promote social problems for M.Ed female students. The students need to raise fees and they are the ones who face shortages at home. While both women and men enjoy autonomy in spending some proportions of household incomes, they have distinctly different spending patterns (SARDC, 2000). Women tend to spend more on dependents, including members of the extended family and replacing food supplies when they run out, men tend to spend more on themselves.

\section{Aim and objectives of study}

Given the above background, the aim of the study was to examine poverty induced deviant activitieson female teachers and female students. In this regard the study sought to:

- Explore deviant activities that female teachers engage in as a result of socio-economic factors.

- Establish deviant activities that female teachers are forced into as students as a result of socioeconomic factors.

\section{Methodology}

The study adopted the survey research design, which falls under the qualitative paradigm. Borg and Gall (1989), state that survey research is a distinctive research methodology that owes much of its recent development to the field of sociology. Data collection tools are used in survey to obtain standardized information from all subjects in the sample. In-depth interviews and observation were the main research instrument. Informal conversational interviews and focus group interviews were also used to triangulate in-depth interviews. The study focused on all thirty M.Ed female block release students of the August 2006 intake at a State University in Zimbabwe. In this study, the sample comprised of the whole population which was thirty female students. The participants were selected using a combination of convenient and purposive sampling techniques.

\section{Findings and discussion}

To respond to the research objectives, the data was presented in text form supported by tables. This is because the concern was not to quantify or find the number of respondents facing a particular problem, but the real focus of the research was to unearth teacher deviant activities. This is consistent with the methods used to gather data, which are in-depth interviews and focus group interviews. A total of five focus group interviews were held. Each focus group had an average of six people. In addition informal conversational and observation were done throughout the entire research period. Social problems associated with poverty, which arose from the research, are discussed under the following categories: deviance, family instability and stress.

\section{Deviance activities}

As highlighted by the objectives the study sought to explore the poverty induced deviance of females as teachers and as students. Table 1 below summarizes deviant activities that female teachers are forced into and table 2 summaries deviant activities as students.

\section{Table 1 Summary of responses related to deviance as teachers}

\begin{tabular}{|l|l|l|l|}
\hline Response & $\mathbf{N}$ & $\mathbf{\%}$ & Rank order \\
\hline Illegal selling of foodstuff to pupils at school & 8 & 26.7 & 2 \\
\hline Abusing the sick leave provisions & 4 & 13.3 & 3 \\
\hline Giving less written work to pupils to reduce work & 16 & 53.3 & 1 \\
\hline Having hair plaited by pupils & 2 & 6.7 & 4 \\
\hline Total & $\mathbf{N = 3 0 \%}$ & $\mathbf{1 0 0 \%}$ & \\
\hline
\end{tabular}


Table 2:Summary of responses related to deviance as students

\begin{tabular}{|l|l|l|l|}
\hline Indicator & $\mathbf{N}$ & $\mathbf{\%}$ & Rank order \\
\hline Failing to set aside adequate study time & 10 & 33.3 & 2 \\
\hline Played truant at college & 17 & 56.7 & 1 \\
\hline Coping assignments & 3 & 10 & 3 \\
\hline Total & $\mathbf{N = 3 0 \%}$ & $\mathbf{1 0 0 \%}$ & \\
\hline
\end{tabular}

We further used the thematic concept of deviance to refer to those activities that female students engage in when they fully know that they are not expected to engage in, at work or at college.

Seventeen observed respondents, out of $30(56.7 \%)$ revealed that control of teachers in schools have become ineffective. We could also substantiate the above findings from our own observations as teachers. The respondents brought out the fact that they have also joined cross border activities, traveling into neighboring countries to obtain goods that will be sold later. These activities are sometimes carried out during working hours. They went on to say that they are increasingly depending on some selfemployment in the informal sector that does not have benefits such as housing allowances or medical aid facilities. Thus, they do not want to fully get into self-employment so they play truant with the employer to keep hanging on to their jobs because they believe that the downward economic performance will not continue forever. Also the findings revealed that the respondents know that they are expected to be at their work places but staying there would mean starvation for the families, hence they look for alternative ways to support their families.

Interviews further revealed that in spite of notices at their schools, boldly stating that it is an act of misconduct for teachers to sell foodstuff to pupils, they went ahead and sold their wares $(26.7 \%)$. Hence, more females are found wanting more than males. The female interviewees reasoned that they are the ones who are more affected by shortages at home as they spend time with their children. If there is no food, children naturally expect mothers to provide. They also revealed that in the presence of members of the extended family, it is mostly women who may be seen as if they are stingy, even in cases where food may be inadequate. This confirms Merton's statement that norms do not work with social reality, in times of crisis or shortages people tend to behave in unexpected ways.

According to Karl Marx's concept of alienation, deviant behavior is a by-product of economic inequalities. The interviews revealed that four of the thirty (13.3\%) respondents had to resort to deviant behavior such as abusing the sick leave facility in order to be away from work and join informal traders. They would therefore lie to school authorities and fake illnesses so as to be away from work and find time for income generating activities, thereby leaving classes unattended.

Also brought to light by the interviews was the fact that female students are frustrated with their salaries. As a result, 53.3\% admitted that they give less written work than prescribed by ministerial regulations. Some, of it is given to pupils to mark, as more time is needed to map out strategies for moneymaking activities.

From the interview findings, $6.7 \%$ of the female students became deviant out of desperation. They disclosed that they even had to resort to having their hair plaited by pupils within the school premises, as they could not afford to go to hair salons. They knew it was not allowed but they were expected to be presentable at work. These further revealed that any deviant activity that would benefit them was welcome because they had become society's laughing stock because of the paltry government salary.

Observation also revealed that deviance by female students was not just at work, but at college as well. $10 \%$ of the respondents admitted that they have a lot of activities to engage in, in some attempts to raise funds. At times they become too busy to work on their assignments. As a result they resort to asking for 
assignments from colleagues to copy. I observed that they would make changes here and there for lectures not to notice. They admitted however, that this is not done on every assignment, but all the same this is deviance.

Though most of the above activities are clearly deviant, some of the respondents confessed that they are proud of the behavior. They even think of themselves as smart for fighting out ways to avoid being stopped by heads of schools. Deviance is then a complex concept. Sometimes it is trivial but at other times it is profoundly harmful. Losing one or two lessons for a teacher may appear trivial but the consequences may be harmful to the pupils for the rest of their lives.

However, while respondents felt that they somehow benefited from deviant activities in terms of money and foodstuff, observation revealed that most of their study time is taken up by activities aimed at fighting poverty in the family (33.3\%). They admitted that such movements compromise the quality of assignments they produce and their preparation for examination is not thorough. The above revelations point to the fact that poverty can force female teachers to be deviant. Activities they engage in constrain their education. Nevertheless, these female students do not give up their studies but they strike a balance between their studies and their economic activities.

\section{Discussions and interpretation}

The study has shown the experiences that female students go through at home, at work and at college due to poverty. In times of poverty female students learn, not because they are motivated but because once they are equipped with a higher degree they hope to escape from poverty.

Poverty threatens the stability of society by undermining the stability of the family. Parents are forced to be busy in income generating activities, thus leaving less time for socializing their children. Due to poverty, accessing education is difficult for women who come from families where there are conflicts. In order to attain education, such women have an extra push that keeps them going. They are great because they overcome great odds caused by poverty.

In times like these, when many people are affected by the downward economic performance of the country, many females in education have strength and determination that makes them remain in the educational race. As found in the study, poverty causes stress but this does not deter female students from pursuing their studies, even though stress is a health related problem that would require them to seek medical attention.

Within family set-ups, there are specific roles and expectations for respective family members. Families depend on their specific roles in making life comfortable presumably for every family member. Unfortunately, poverty is forcing most women to carry out their husbands' roles as well. The findings have shown that most women are living as lone parents. Thus, because of these roles, the barrier for females in higher education is so subtle that it is transparent, yet so strong that it prevents them from moving smoothly up the educational ladder.

The findings imply that the teaching profession is currently characterized by frustrated and alienated workers who just hang on to their jobs hoping and waiting for salary reviews. As a result, the education of the pupils in schools is compromised because not only are female M.Ed students but also their counterparts are equally frustrated. Furthermore, the teaching profession has social expectations, regulations and principles that determine teacher conduct and ethical foundations crucial for its survival. Sadly though, the findings imply that poverty forces female teachers to disregard most ethical considerations and they become deviant. As a result, most female teachers automatically develop survival skills to avoid starvation as well as to acquire higher education. 
On the whole, poverty devalues and debases the standard of quality of life among female professionals. The study has shown that graduate teachers would devalue themselves in neighboring countries by doing menial jobs.

\section{REFERENCES}

1. Bogdan, R.C. \&Bilken, S.K. (1992). Qualitative Research: An Introduction to Theory and Methods. Boston, Allyn and Bacon.

2. Byrne, D. (1999) Social Exclusion: Buckingham Open University Press

3. Haralambos, M. \&Holborn, M. (2000) Themes and Perspectives. London, Harper Collins Publishers. Ltd.

4. Haralambos, M. and Holborn, M. (2013).Sociology Themes and Perspectives $8^{\text {th }}$ edition. London Harper Collins

5. Merton R.K. 1957. Social Theory and Social Structure. 2nd Edition. New York.Amazon Books.

6. Mingione, E. (1996) Urban Poverty and the Underclass: A Reader, Oxford, Blackwell

7. People Magazine http://www.peoplemagaz/adaptn/0208.htm

8. SARDC (2000) WIDSAA, Beyond Inequalities: Women in Southern Africa. Harare SARDC. 